\title{
The effects of major genes on quantitatively varying characters in barley. 4. The GPert and denso loci and quality characters
}

\author{
W. T. B. THOMAS, W. POWELL \& J. S. SWANSTON \\ Scottish Crop Research Institute, Invergowrie, Dundee DD2 5DA, UK
}

\begin{abstract}
Random inbred lines derived by doubled haploidy and single seed descent were used to demonstrate that the GPert dwarfing gene, as found in cv. Golden Promise, was associated with low thousand corn weight, main-stem, single plant and plot yield and hot water extract, and high milling energy and levels of screenings. Similarly, the denso dwarfing gene was shown to be associated with late heading, low thousand corn weight, main-stem and single plant yield and high levels of $\beta$-glucan and screenings. The associations of the GPert locus with main-stem, single plant and plot yield milling energy and screenings, and of the denso locus with main-stem and single plant yield, were shown to be a result of their association with thousand corn weight. The association of the GPert locus with hot water extract was most likley to be due to linkage, and genes controlling the character may be located on barley chromosome 7 . The denso gene may also be linked to genes that control heading date, height, screenings and $\beta$-glucan but the chromosomal location of the denso gene is unknown. Amongst lines that possess the GPert gene, correlations between characters were such that the probability of producing a line to combine a high level of plot yield and hot water extract with the dwarfing gene was low.
\end{abstract}

Keywords: barley, linkage/pleiotropy, major genes, polygenes, quality, yield.

\section{Introduction}

In the evaluation of breeding progress from 1880 to 1980, Riggs et al. (1981) concluded that the yield of spring barleys increased over the period whilst plant height decreased. Many breeding programmes use recessive dwarfing genes to reduce plant height and increase resistance to lodging and a large number of European spring barley cultivars possess the denso gene (European Brewery Convention, 1989) which confers a semi-dwarf stature and a semi-prostrate juvenile growth habit. Of the cultivars that appeared in the UK seed certification scheme on mainland UK in 1989 , those that possessed the denso gene accounted for approximately 74 per cent of the area and those that possessed the erectoides GPert gene, which also confers a semi-dwarf structure but an erect juvenile growth habit, occupied approximately 8 per cent of the total UK area but over 17 per cent of the Scottish area (NIAB, 1989; DAFS, 1989).

The GPert gene has been shown to be associated with low thousand corn weight, main-stem, single plant and plot yield (Powell et al., 1985c) and the denso gene with late heading and maturity, low thousand corn weight and single plant yield (Ali et al., 1978; Snape \& Simpson, 1981a; Powell et al., 1985b). Given that both genes are associated with deleterious effects upon yield and agronomic characters, it is important to determine whether or not they also have deleterious associations with quality characters, particularly as some 20 per cent of the UK barley crop is malted (European Brewery Convention, 1989). The dwarfing gene induced in cv. Jotun has been shown to be allelic to the denso gene in cvs Maris Mink and Diamant (Haahr \& von Wettstein, 1976) and to be associated with significantly lower hectolitre weight, a lower (but not significantly so) percentage of plump kernels and a slightly lower level of hot water extract, although devels of significance could not be attached to the last difference (Foster \& Thompson, 1987). No association was detected, however, between the GPert locus and $\beta$ glucan content (Powell et al., 1985a).

Random inbred lines produced by doubled haploidy and single seed descent have been used to identify associations of the GPert, denso, day-length insensitivity and six-row/two-row loci with quantitative 
characters (Powell et al., 1985b and c, 1990). This technique can indicate whether the association is due to pleiotropy or linkage in addition to revealing character associations. Such an approach will enable the breeder to choose the appropriate strategy to deploy the GPert and denso genes as well as to help locate genes that control quantitative traits.

\section{Materials and methods}

Forty-four inbred lines were produced from each of two spring barley crosses, TS311 (TS42/3/5 $\times \mathrm{cv}$. Apex) and TS332 (TS57/72/6 $\times$ cv. Keg). TS42/3/5 and TS57/72/6 are SCRI breeding lines which carry the GPert and denso dwarfing genes, respectively, whereas Apex and Keg do not carry any major dwarfing genes. For each cross, 22 of the lines were doubled haploids $(\mathrm{DH})$ produced from the $\mathrm{F}_{1}$ by the Hordeum bulbosum method (Kasha \& Kao, 1970) and the remaining lines were produced by single seed descent (SSD) up to the $\mathrm{F}_{5}$ generation. The SSD and DH lines were then multiplied in the field for two seasons before growing with 12 controls in four replicated 100-entry field trials at the Scottish Crop Research Institute, Dundee in 1987. There was insufficient seed from the parents for them to be included in the trials. Trials 1 and 2 received 45, 22.5 and 22.5 and trials 3 and 4 , $135,67.5$ and $67.5 \mathrm{~kg} / \mathrm{ha}$ of $\mathrm{N}, \mathrm{P}$ and $\mathrm{K}$, respectively. Trials 1 and 3 were also sprayed with fungicide to control foliar pathogens whereas trials 2 and 4 were not so that the trials represented four different treatments. The plots were scored for juvenile growth habit to identify the presence or absence of the GPert or denso dwarfing genes. The heading date (HD) was recorded as the number of days after 1 June by which the majority of the plot had reached GS53. The height $(\mathrm{cm})$ from the ground to the collar was recorded at GS85 $(\mathrm{Ht})$. Five single plants were taken from each plot at maturity and the weights (g) of grain from the main-stem (defined as the tallest stem) and the whole plant (MSY and SPY respectively) were later determined in the laboratory. The plots were harvested with a plot combine and the yields $(P Y)$ recorded in tonnes per hectare after drying to a constant moisture. Grain from the plots was cleaned and the portion that passed through a $2.2 \mathrm{~mm}$ sieve was weighed and expressed as a percentage of the cleaned sample [screenings $(<2.2$ $\mathrm{SV})$ ]. Grain retained by the sieve was then used to determine thousand corn weight $(\mathrm{g})(T C W)$. The percentage grain nitrogen $(\mathrm{N})$ and $\beta$-glucan $(\mathrm{BG})$ contents were assessed by near infra-red reflectance (Allison et al., 1978), milling energy (joules) (ME) by the modified Comparamill (Cowe et al., 1989) and hot water extract (litre degrees $/ \mathrm{kg}$ ) (HWE) following modified decro-malting (Swanston \& Taylor, 1990).

\section{Results}

For each cross, the lines can be classified into groups that possess and lack the dwarfing gene (dwarf and tall respectively). There were significantly fewer dwarf lines than expected in the SSD population from TS311 (Table 1), which suggests non-random loss in this case. Otherwise, the segregation of the dwarfing genes was as expected.

The data were analysed using a mixed model with trials and lines fixed and reps random effects. The trials $\times$ lines item was significant for four characters in TS311 (Table 2) and three characters in TS332. However, the magnitude of this component of variance was generally small. There were significant differences between trials in most cases, the exceptions being for milling energy and hot water extract in both crosses, height and main-stem yield in TS311, and single plant yield in TS332. The between-lines item was highly significant in each analysis, which indicates the presence of significant genetic variation for each character in both crosses. The between-lines component of variation was taken as an estimate of the additive genetic variation $\langle D\rangle$ for the $\mathrm{DH}$ lines, although it might be inflated by the presence of epistatic effects between homozygous alleles. As the SSD lines were $F_{8}$ bulks of $F_{5}$ single plants, the between-families component of variation estimated $15 / 16 D$, assuming $15 /$ $16384 \mathrm{H}$ is negligible, and will also be biased by similar epistatic effects.

The sum of squares associated with the dwarfing gene (the between-groups item) is the between-lines sum of squares for the whole cross less the total of the sum of squares for the between-lines within groups. In this case, it has one degree of freedom and its significance is tested against the between-lines within groups mean square. There were significant differences

Table 1 Classification of doubled haploid $(\mathrm{DH})$ and single seed decent (SSD) lines from TS311 and TS332 into groups possessing (Dwarf) and lacking (Tall) a dwarfing gene

\begin{tabular}{llrl}
\hline & Dwarf & Tall & $\chi_{[1\}}^{2}$ \\
\hline TS311 DH & 11 & 11 & 0 \\
TS311 SSD & 18 & 4 & $8.91^{* *}$ \\
TS332 DH & 11 & 11 & 0 \\
TS332 SSD & 14 & 8 & 1.64 \\
\hline
\end{tabular}

$* *=P<0.01$ 


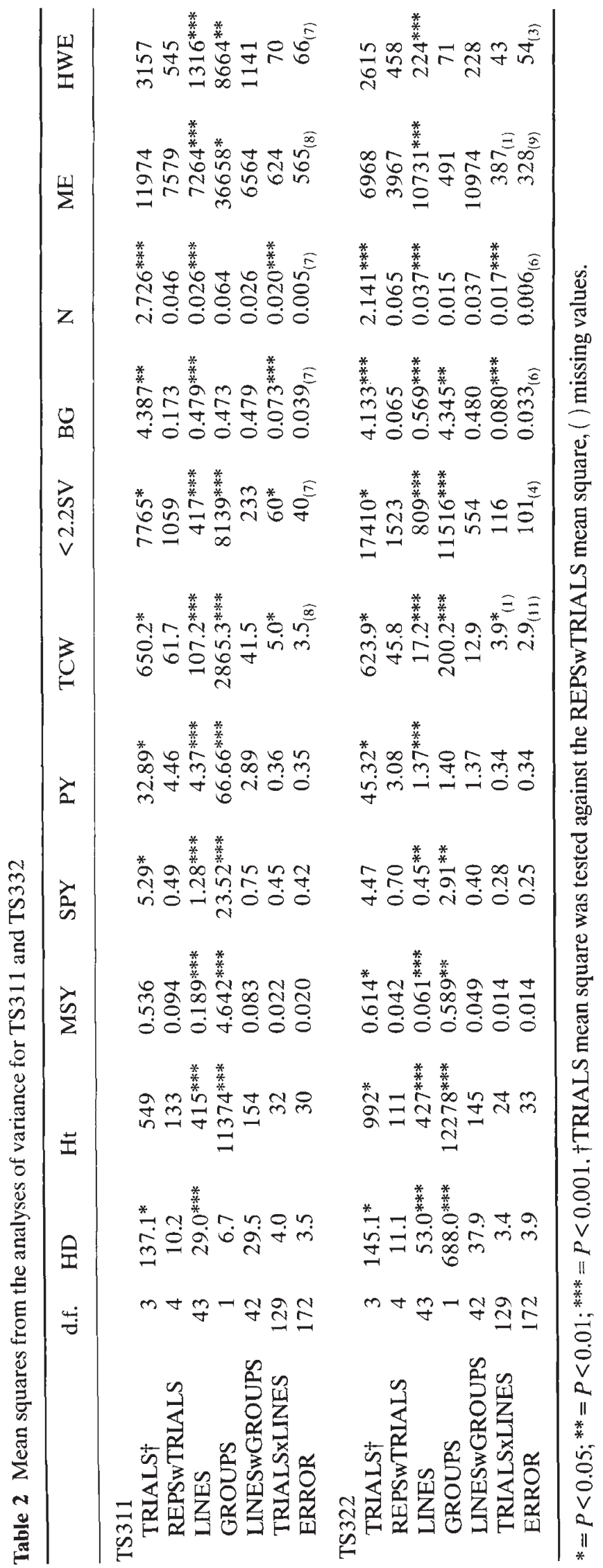

between groups for all the characters measured on TS311 with the exception of the heading date, $\beta$-glucan and nitrogen (Table 2). The dwarf group had a lower main-stem yield, single plant yield, plot yield, thousand corn weight and hot water extract and greater screenings and milling energy than the tall group (Table 3 ). There were also significant differences between groups for most of the characters from TS332, the exceptions being yield, nitrogen, milling energy and hot water extract (Table 2). The denso group also had a lower main-stem and single plant and thousand corn weight and greater screening, and had, in addition, a greater $\beta$-glucan content and later heading date than the tall group (Table 3 ). Both gene loci are therefore significantly associated with a number of quality characters in addition to yield and agronomic characters.

Estimates from $F_{1} D H$ and SSD populations of the portion of additive genetic variation $(D)$ will differ if genes that control a character are predominantly linked in one phase (Jinks \& Pooni, 1981; Snape \& Simpson, 1981b). This can be tested by fitting models to the between lines and error items of the analyses of variance for each group and allowing the error terms for each group to take their own values whilst fitting a common value for $D$. If the model fails then the two estimates of $D$ are significantly different (Pooni et al., 1980).

The estimate of $D$ from the doubled haploid lines from TS311 was significantly greater than that from the SSD lines for height, thousand corn weight, $\beta$-glucan and hot water extract (Table 4), which suggests an excess of genes linked in the coupling phase that controls these characters. There were significantly fewer dwarf lines in the SSD population, however, and previous work has shown the GPert gene is associated

Table 3 Means of the dwarf and tall groups within TS311 and TS332

\begin{tabular}{lccccc}
\hline & \multicolumn{3}{l}{ TS311 } & & \multicolumn{2}{l}{ TS332 } \\
\cline { 2 - 3 } \cline { 6 - 6 } & Dwarf & Tall & & Dwarf & Tall \\
\hline HD & 33.92 & 34.22 & & 39.00 & 36.18 \\
Ht & 65.52 & 77.51 & & 62.19 & 74.12 \\
MSY & 0.6960 & 0.9387 & & 0.6425 & 0.7251 \\
SPY & 1.845 & 2.390 & & 1.622 & 1.805 \\
PY & 3.355 & 4.273 & & 2.768 & 2.896 \\
TCW & 32.29 & 38.33 & & 33.25 & 34.78 \\
$<2.2 S V$ & 24.94 & 14.90 & & 41.66 & 30.06 \\
BG & 2.412 & 2.333 & & 2.190 & 1.966 \\
N & 2.044 & 2.034 & & 2.074 & 2.087 \\
ME & 682.7 & 661.2 & & 614.9 & 622.3 \\
HWE & 285.9 & 295.9 & & 295.6 & 294.3 \\
\hline
\end{tabular}


Table 4 Estimates of the additive genetic $(D)$ comonents of variation from single seed descent (SSD) and doubled haploid (DH) lines from TS311 and TS332 and Chi-square test of significance of differences between them.

\begin{tabular}{|c|c|c|c|c|c|c|c|}
\hline & \multicolumn{4}{|l|}{ TS311 } & \multicolumn{3}{|l|}{ TS332 } \\
\hline & $D_{(\mathrm{SSD})}$ & $D_{(\mathrm{DH})}$ & $\chi_{[1]}^{2}$ & $\chi_{|1|}^{2} \dagger$ & $D_{(\mathrm{SSD})}$ & $D_{(\mathrm{DH})}$ & $\chi_{[1]}^{2}$ \\
\hline HD & 2.511 & 4.196 & 1.05 & 0.43 & 6.816 & 3.557 & 1.74 \\
\hline $\mathrm{Ht}$ & 15.80 & 74.91 & $7.78^{* *}$ & 0.00 & 61.70 & 43.99 & 0.50 \\
\hline MSY & 0.01543 & 0.02736 & 1.30 & 0.16 & 0.00557 & 0.00504 & 0.03 \\
\hline SPY & 0.1123 & 0.1328 & 0.02 & 0.95 & 0.0574 & 0.0256 & 0.95 \\
\hline PY & 0.3410 & 0.6868 & 2.02 & 0.14 & 0.1141 & 0.0967 & 0.07 \\
\hline TCW & 6.147 & 20.480 & $5.78^{*}$ & 1.45 & 1.413 & 2.051 & 0.45 \\
\hline$<2.2 \mathrm{SV}$ & 32.90 & 61.44 & 1.61 & 0.37 & 90.24 & 80.02 & 0.06 \\
\hline BG & 0.02754 & 0.08903 & $4.93^{*}$ & 3.43 & 0.10203 & 0.04781 & 2.49 \\
\hline $\mathrm{N}$ & 0.00303 & 0.00233 & 0.22 & 0.14 & 0.00346 & 0.00520 & 0.61 \\
\hline ME & 794.9 & 988.3 & 0.21 & 0.00 & 1713.3 & 892.2 & 1.97 \\
\hline HWE & 63.22 & 239.11 & $6.50^{*}$ & 0.19 & 19.83 & 25.05 & 0.16 \\
\hline
\end{tabular}

$* P<0.05 ; * *=P<0.01$.

$\dagger=$ Tall groups only.

with variation for thousand corn weight as well as height (Powell et al., 1985c). It is possible that the differences between populations reflect the lack of dwarf lines in the SSD population. This is confirmed by the absence of significant differences in the estimates of $D$ from the tall sub-groups of the DH and SSD populations (Table 4). None of the chi-squares were significant for TS332 (Table 4), which indicates the absence of detectable genetic linkages in any one phase controlling the characters studied.

The magnitude of the portion of additive genetic variation associated with the gene locus is the reduction in $D$ when it is estimated from the total of the between-lines within groups component of variation compared to the estimate from the between-lines component of variation for the cross (Al Banna et al., 1984). Table 5 shows that the GPert locus was associated with over 60 per cent of the additive genetic variation for height, main-stem yield, single plant yield and thousand corn weight. The locus was also associated with over 33 of the additive genetic variation for plot yield and screenings and 10 per cent for milling energy and hot water extract. The denso gene locus was associated with over 70 per cent of the additive genetic variation for height, over 25 per cent of that for heading date, main-stem yield, single plant yield, thousand corn weight and screenings and over 16 per cent of that for $\beta$-glucan (Table 5).

As there were very few dwarf lines in the SSD group of TS311, comparison of the estimates of $D$ from the $\mathrm{DH}$ and SSD groups cannot be made to reveal whether or not the association of the GPert locus is due to pleiotropy or linkage. It can be done for the denso locus, using similar model fitting methods to those described earlier but the test is not very sensitive and will only detect large changes in the portions of $D$ associated with a gene locus (Powell et al., 1990). If the percentages of $D$ associated with the denso gene are compared for the DH and SSD groups, it can be seen that there is a considerable decrease in the SSD group for heading date, single plant yield and screenings and an increase in main-stem yield and $\beta$-glucan (Table 6). This suggests that the association may be due to linkage disequilibrium for these characters. There was little change in the percentages associated for thousand corn weight which suggests that the denso gene is very closely linked to the character or that it has pleiotropic effects on it. There was also a major reduction in the percentage of $D$ associated with the denso gene in the SSD group for height. This may be due to linkage of the denso dwarfing gene to other genes that control height.

The 55 pairwise correlations between the 11 characters can be compared between the dwarf and tall groups for each cross. There are three correlations that can be derived from these data: correlations between line means represent phenotypic correlations, the additive genetic components of variance and covariance can be used to derive additive genetic correlations and the error correlations can be obtained similarly. In this study, all three correlations were very similar, so the phenotypic correlations alone have been presented since levels of significance can be attached to them.

There were 18 and 17 significant correlations in the dwarf and tall groups respectively for TS311 (Table 7). All the significant correlations in the tall group 
Table 5 Estimates of the total additive genetic variation $(D)$ and the amount associated with the GPert and denso loci in TS311 and TS332, respectively

\begin{tabular}{lccccccc}
\hline & \multicolumn{5}{c}{ TS311 } & \multicolumn{2}{l}{ TS332 } \\
\cline { 2 - 4 } \cline { 6 - 8 } & $D$ (Total) $)$ & $D($ GPert $)$ & $\% D($ GPert $)$ & $D$ (Total) & $D($ denso $)$ & $\% D($ denso $)$ \\
\hline HD & 3.394 & 0.0 & 0.0 & & 6.550 & 2.016 & 30.78 \\
Ht & 51.27 & 34.79 & 67.85 & & 52.55 & 37.62 & 71.59 \\
MSY & 0.0226 & 0.0141 & 62.64 & & 0.0063 & 0.0017 & 26.55 \\
SPY & 0.1148 & 0.0706 & 61.50 & & 0.0265 & 0.0078 & 29.35 \\
PY & 0.5362 & 0.1978 & 36.88 & & 0.1376 & 0.0 & 0.0 \\
TCW & 13.81 & 8.76 & 63.36 & & 1.91 & 0.58 & 30.49 \\
$<2.2 S V$ & 50.15 & 24.51 & 48.87 & & 94.43 & 33.99 & 35.99 \\
BG & 0.0585 & 0.0 & 0.0 & & 0.0716 & 0.0120 & 16.74 \\
N & 0.00274 & 0.0 & 0.0 & & 0.00414 & 0.0 & 0.0 \\
ME & 893.1 & 93.3 & 10.40 & & 1386.9 & 0.0 & 0.0 \\
HWE & 166.75 & 23.32 & 13.99 & & 22.60 & 0.0 & 0.0 \\
\hline
\end{tabular}

Table 6 Amount of additive genetic variation associated with the denso locus $\left(\% D_{\text {(denso) }}\right)$ for the doubled haploid $(\mathrm{DH})$ and single seed descent (SSD) populations from TS 332

\begin{tabular}{lrr}
\hline & \multicolumn{2}{l}{$\% D_{(\text {denso })}$} \\
\cline { 2 - 3 } & $\mathrm{DH}$ & $\mathrm{SSD}$ \\
\hline $\mathrm{HD}$ & 71.8 & 32.7 \\
$\mathrm{Ht}$ & 88.6 & 56.6 \\
MSY & 0.0 & 34.6 \\
SPY & 37.4 & 0.0 \\
TCW & 26.1 & 32.0 \\
$<2.2 \mathrm{SV}$ & 48.7 & 33.2 \\
BG & 0.0 & 49.1 \\
\hline
\end{tabular}

involved height, main-stem yield, plot yield or thousand corn weight. Eleven of the correlations were also significant in the dwarf group. The only significant correlations involving hot water extract were negative associations with main-stem yield and thousand corn weight. By constrast, there were five significant correlations involving hot water extract in the dwarf group. Hot water extract showed significant negative correlations with plot yield, main-stem and single plant yield and thousand corn weight and a positive correlation with screenings. There were significant negative correlations between milling energy and both heading date and height.

For TS332, 16 and 11 of the correlations were significant for the denso and tall groups, respectively (Table 7). Eight correlations were significant in both groups and five of these were also significant in the groups from TS311; positive correlations between height and thousand corn weight and main-stem and single plant yield and negative correlations between plot yield and nitrogen, plot yield and screenings, and thousand corn weight and screenings. The only correlation that involved hot water extract was a positive one with height in the denso group and the only other correlations of note in this group were positive ones between $\beta$-glucan and both nitrogen and milling energy.

\section{Discussion}

The association between the GPert locus and additive genetic variation for thousand corn weight, plot, mainstem and single plant yield was found in an earlier study of three barley crosses involving genotypes with the GPert gene (Powell et al., 1985c). The phenotypic correlations between thousand corn weight and plot, main-stem, single plant yield and screenings over all the lines from TS31. were $0.78,0.89,0.71$ and -0.85 (all $P<0.001$ ) respectively. This suggests that the association of the GPert locus with additive genetic variation for the yield characters and screenings was due to its association with thousand corn weight. If the yield and screenings data are analysed with thousand corn weight as a co-variate then there are no significant differences between the dwarf and tall groups so the GPert locus was not associated with any of the additive genetic variation for these characters. A quantitative trait locus that controls thousand corn weight $(K w 1)$ has been found to be associated with a gene locus on barley chromosome 7 which controls rachilla hair length (Jensen, 1989) and the GPert locus has been found to be linked to the rachilla hair length locus 


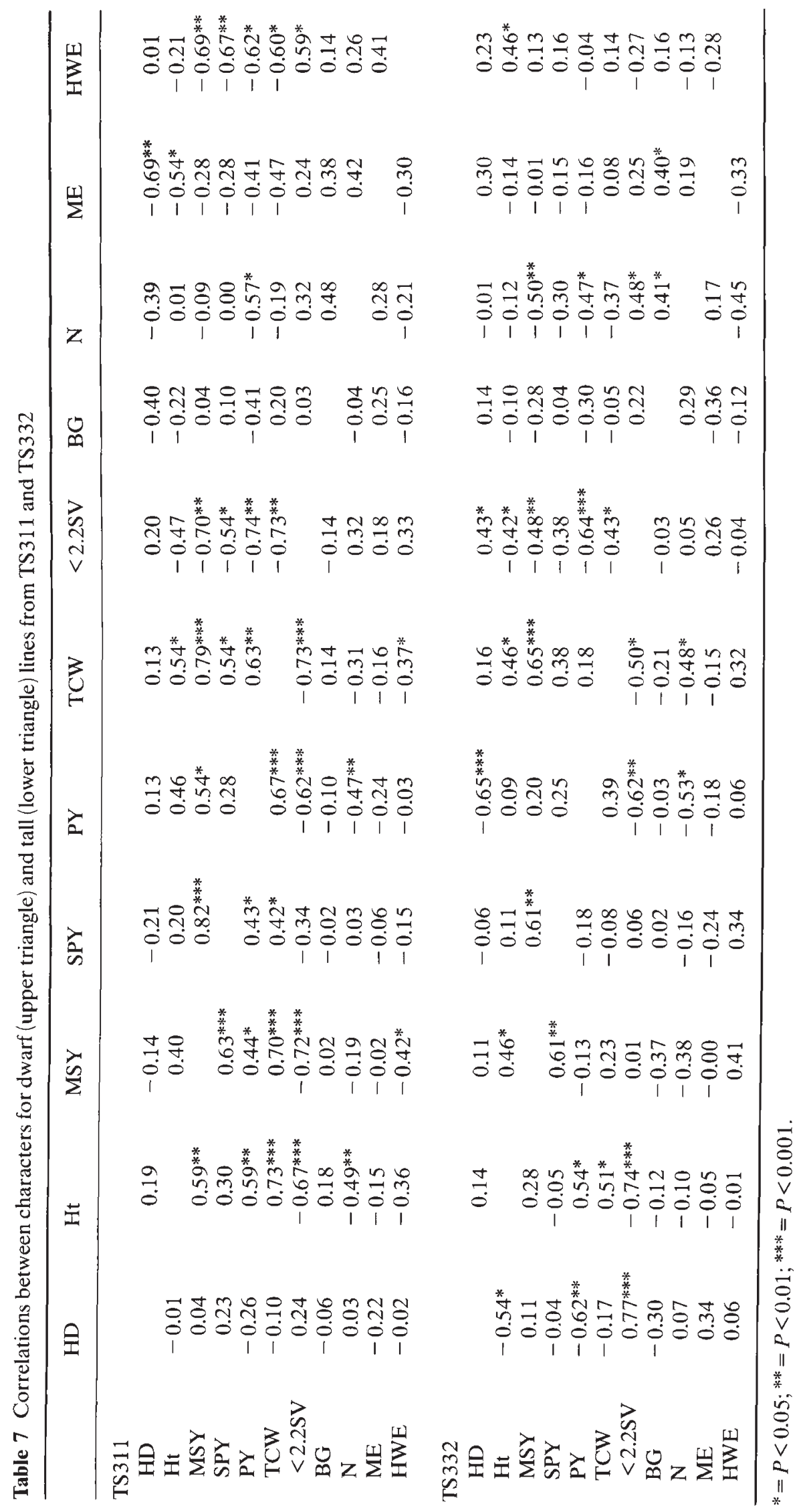


(Thomas et al., 1984). The assocation of the GPert locus with thousand corn weight may therefore be because it is linked to $K w 1$, although the two experiments report that the genes are on different arms of the chromosome.

Thousand corn weight was also negatively correlated with milling energy $(r=-0.45, P<0.01)$ and the difference between groups was also non-significant after analysing the data with thousand corn weight as a co-variate. A study of wheat aneuploid and alien addition lines showed that genes that control milling energy were located on the homoeologous group 5 chromosomes, which are equivalent to barley chromosome 7 (Forster \& Ellis, 1990) and the GPert gene has been located on barley chromosome 7 (Thomas et al., 1984). Results from this suggest that there is no linkage between the GPert locus and the genes that control milling energy.

There were no significant correlations between hot water extract and any of the other characters over all the lines from TS311, so there is a genuine association between the GPert locus and the additive genetic variation that controls the character. In this study, the GPert gene was associated with reduced hot water extract whereas cv. Golden Promise, with the GPert gene, has a slightly higher hot-water extract than its parent cv. Maythorpe (Swanston et al., 1991). Whilst these two findings may seem slightly anomalous they do suggest that the association is the result of linkage rather than pleiotropy and that some of the genes that control hot water extract may be located on barley chromosome 7 .

The GPert gene also causes insensitivity to exogenously applied gibberellic acid (Hanson et al., 1980) as do the wheat dwarfing genes at the $R h t$ locus (Gale \& Marshall, 1973). The Rht alleles also cause a reduction in grain weight but this is more than compensated for by an increase in grain number due to increased spikelet fertility, resulting in an overall increase in yield (Gale \& Youseffian, 1985). Breadmaking quality, including milling properties, appears largely unaffected by the Rht 3 allele (Flintham \& Gale, 1982) but the gene locus is located on the homoeologous group 4 chromosomes (McVittie et al., 1978) whereas the location of the GPert gene on barley chromosome 7 means that it is on homoeologous group 5 chromosomes.

The association of the denso gene with a later heading date, lower thousand corn weight and single plant yield has been reported from other studies (Ali et al., 1978; Snape \& Simpson, 1981a; Foster \& Thompson, 1987). Our results confirm these findings and also show that the denso gene is associated with a reduced main-stem yield and increased levels of screenings and $\beta$-glucan but that it is not associated with hot-water extract. The lack of association of the denso gene with hot water extract is confirmed by the fact that European cultivars that possess the gene, combined with very high levels of hot water extract, have been developed (Larsen \& Weilenmann, 1989).

Correlations between all the TS332 lines revealed significant values between thousand corn weight and main-stem yield $(r=0.60, P<0.001)$, single plant yield $(r=0.33, P<0.05), \beta$-glucan $(r=-0.32, P<0.05)$ and screenings $(r=-0.62, P<0.001)$. The associations between the denso locus and main-stem and single plant yield, $\beta$-glucan and screenings may therefore be a result of the association of the locus with thousand corn weight. If the data for these characters are analysed with thousand corn weight as a co-variate, significant differences are still observed between groups for $\beta$-glucan and screenings but not for mainstem and single plant yield. The denso locus has not yet been assigned to any one barley chromosome so whilst it would appear that some of the genes that control heading date, $\beta$-glucan and screenings are linked to the denso locus, they cannot be identified with any particular barley chromosome.

An earlier study had shown random inbred lines with the GPert gene to be more environmentally sensitive for plot yield than lines without the gene (Ellis \& Brown, 1986) but there were no significant genotype $\times$ environment interactions for plot yield in TS311, which segregated for the GPert gene. The significant interactions for thousand corn weight and screenings in TS311 disappear when the tall and dwarf groups are considered separately. For $\beta$-glucan and nitrogen, there were significant genotype $\times$ environment interactions for both groups. Significant genotype $\times$ environment interactions for $\beta$-glucan and nitrogen were also found in both groups for TS332 and in the dwarf group for thousand corn weight.

This is the first report of a study of the relationship between milling energy and hot water extract amongst inbred lines within crosses, rather than a specially selected sample of genotypes, and the lack of correlation between the two characters contrasts with some previous reports (Allison et al., 1979; Cowe et al., 1989; Swanston et al., 1991), although Ellis et al. (1979) reported a low correlation. However, the nitrogen content of the samples was high (Table 3) and the relationship between milling energy and hot water extract does tend to break down at high levels of nitrogen (M. J. Allison, personal communication). Also, the GPert gene in TS42/3/5 was derived from cv. Midas which has been shown to have a relatively high milling energy but to modify extensively during malting, whereas cv. Keg is a derivative of cvs Proctor and Kneifel and is therefore likely to have a low milling 
Table 8 Probabilities that lines will exeed standards for yield, hot-water extract and height and minimum population sizes required to have a 95 per cent probability of producing such a line

\begin{tabular}{lcccr}
\hline & \multicolumn{2}{c}{$>\mathrm{PY},>\mathrm{HWE}$} & & \multicolumn{2}{c}{$<\mathrm{PY},<\mathrm{HWE},<\mathrm{Ht}$} \\
\cline { 2 - 5 } & Probability & Population & Probability & Population \\
\hline TS311 dwarf & 0.005534 & 540 & 0.002889 & 1036 \\
TS311 tall & 0.305172 & 9 & 0.000206 & 14541 \\
TS332 dwarf & 0.000486 & 6163 & 0.000474 & 6319 \\
TS332 tall & 0.000229 & 13081 & 0.000000 & $>1000000$ \\
\hline
\end{tabular}

energy but modify slowly (Swanston et al., 1991). TS57/72/6 has both Midas and Proctor in its parentage so there are a number of possible combinations of milling energy and modification rates over the two crosses. If a combination of high milling energy and rapid modification predominates over the two crosses then the correlation between milling energy and hot water extract will be poor.

From the breeding aspect, the deleterious associations of the denso and GPert genes with quantitative characters have important consequences. Where the association is due to undesirable linkages such as that between the GPert gene and hot water extract, pedigree inbreeding, $\mathrm{DH}$ from later generations or single seed descent would be better options than $\mathrm{F}_{1} \mathrm{DH}$. However, there was non-random loss in the TS311 SSD population in this study and Riggs \& Hayter (1976) also showed that non-random loss occurs in SSD populations so SSD may not be a useful alternative breeding method if a breeder selects for short types. It may even be more efficient to use an alternative breeding strategy such as recurrent selection. If the association is due to favourable linkages then $\mathrm{F}_{1} \mathrm{DH}$ would be the best way to preserve them.

It is also important to note that the GPert gene is associated with low thousand corn weight, and hence low plot yield, and hot water extract. Plot yield is negatively correlated with hot water extract so that it will be difficult for the breeder to combine high plot yield with high hot water extract in a line with the GPert gene. This can be illustrated by using the estimates of the cross mean, additive genetic variances and phenotypic correlation between plot yield and hot water extract to predict the probabilities of obtaining dwarf or tall inbred lines from TS311 that will exceed a given standard. Cultivars Klaxon and Natasha were among the controls grown in this experiment and the standards were chosen to be greater than their mean for hot water extract and greater than their mean plus 10 per cent for plot yield. There was a very high prob- ability of obtaining inbred lines from the tall group of TS311 that would meet the standards - a population of nine would be sufficient to produce such a line at the 95 per cent probability level (Table 8 ). The probability was low for the dwarf group of TS311 and a population of over 500 dwarf lines would be required to ensure the presence of a similar line at the same level of probability. The tall group was much taller than the dwarf and if a height standard of less than the mean of Klaxon and Natasha is added then the situation is reversed. The dwarf population would only need to be doubled to produce a line to meet the standards but a population of approximately 15,000 talls would be required to have a 95 per cent probability of producing such a line (Table 8). However, hot water extract had significant negative and positive correlations with thousand corn weight and screenings respectively in the dwarf lines from TS311 so that, whilst it may be possible to produce a dwarf line with high yield and hot water extract, the levels of screenings may be unacceptably high. The probability of producing a dwarf line from TS332 that met the same standards for height and hot water extract is also low (Table 8), but this is mainly due to the low mean plot yield (Table 3 ) rather than any adverse character associations.

This paper provides further evidence of the power of random inbred lines derived by doubled haploidy and single seed descent in detecting associations between major genes and quantitative characters. The information obtained is of value to breeders in designing their programmes and to geneticists in locating the genes that control quantitative characters.

\section{References}

AL-BANNA, M. K. S., JiNKS, J. L. AND POONI, H. S. 1984. The contribution of pleiotropy at the mop loci to continuous variation in Nicotiana rustica. Heredity, 52, 95-102.

ALI, M. A. M., OKIROR, S. O. AND RASMUSSON, D. C. 1978. Performance of semidwarf barley. Crop Sci., 18 418-422. 
ALLISON, M. J., COWE, I. A., BORZUCKI, R., BRUCE, F. M. AND MCHALE, R. 1979. Milling energy of barley. J. Inst. Brew., 85, 262-264.

ALLISON, M. J., COWE, I. A. AND MCHALE, R. 1978. The use of infra red reflectance for the rapid estimation of the soluble $\beta$ glucan content of barley. J. Inst. Brew., 84, 153-155.

COWE, I. A., CUTHBERTSON, D. C. AND SWANSTON, J. S. 1989. The effect of nitrogen and moisture levels on milling energy of barley. J. Inst. Brew., 95, 423-425.

DAFS 1989. UK Cereal Certification Scheme. Scotland Agriculture Scientific Services.

ELLIS, R. P. AND BROWN J. 1986. Yield in spring barley at contrasting sites in England and Scotland. Ann. Appl. Biol., 109, 613-617.

ELLIS, R. P., SWANSTON, J. S. AND BRUCE, F. M. 1979. A comparison of some rapid tests for malting quality. J. Inst. Brew., 85, 282-285.

EURopean brewery Convention 1989. In: Pierce, J. B. (ed.) Advances in Malting Barley 1989. European Brewery Convention, The Netherlands.

FlintHAM, J. E. AND GALE, M. D. 1983. The Tom Thumb dwarfing gene $R h t 3$ in wheat. II. Effects on height, yield and quality. Theor. Appl. Genet., 66, 249-256.

FORSTER, B. P. AND ELLIS, R. P. 1990. Milling energy requirement of the aneuploid stocks of common wheat, including alien addition lines. Theor. Appl. Genet., 80, 806-809.

FOSTER, A. E. AND THOMPSON, A. P. 1987. Effect of a semidwarf gene from Jotun on agronomic and quality traits of barley. In: Barley Genetics V. Proceedings of the Fifth International Barley Genetics Symposium, Okayama 1986, pp. 979-982.

GALE, M. D. AND MARSHALL, G. A. 1973. Insenitivity to gibberellins in dwarf wheats. Ann. Bot., 37, 729-735.

GALE, M. D. AND YOUSEFFIAN, s. 1985. Dwarfing genes in wheat. In: Russell, G. E. (ed.) Progress in Plant Breeding. Butterworths, London, pp. 1-35.

HAAHR, v. AND VON WETTSTEIN, D. 1976. Studies of an induced high yielding dwarf-mutant of spring barley. Barley Genetics III. Proceedings of the Third International Barley Genetics Symposium Garching 1975, Velag Karl Thiemig, Munich. pp. 215-218.

HANSON, P. R., MCVITTIE, J. A. AND SMALLEY, J. L. 1980. Seedling response to exogenous gibberellic acid in spring barley. $Z$. Pflanzenzucht., 84, 115-121.

JENSEN, J. 1989. Estimation of recombination parameters between a quantitative trait locus (QTL) and two marker gene loci. Theor. Appl. Genet., 78, 613-618.

JINKS, J. L. AND POONI, H. s. 1981. Properties of pure breeding lines produced by dihaploidy, single seed descent and pedigree breeding. Heredity, 46, 391-395.

KASHA, K. J. AND KAO K. N. 1970. High frequency haploid production in barley (Hordeum vulgare L.). Nature., 225, 874-876.

LARSEN, J. \& WeIlenMANn, F. (eds) 1989. Barley \& Malt Group Report on Field Trials 1989, 39. European Brewery Convention, The Netherlands.

MCVITTIE, J. A., GALE, M. D., MARSHALL, G. A. AND WESTCOTT, B. 1978. The intrachromosomal mapping of the Norin 10 and Tom Thumb dwarfing genes. Heredity, 40, 67-70.
NIAB 1989. Cereals Seed Production, England and Wales No. 45, National Institute of Agricultural Botany, Cambridge, UK.

PERSSON, G. AND HAGBERG, A. 1969. Induced variation in quantitative characters in barley. Morphology and cytogenetics of erectoides mutants. Hereditas, 61, 115-178

POONI, H. S. AND JINKS, J. L. 1978. Predicting the properties of recombinant inbred lines derived by single seed descent for two or more characters simultaneously. Heredity, $\mathbf{4 0}$, 349-361.

POONI, H. S., JINKS, J. L. AND POONI, G. S. 1980. A general method for the detection and estimation of additive, dominance and epistatic variation for metrical traits IV. Triple test cross analysis for normal families and their selfs. Heredity, 44, 172-192.

POWELL, w., ELLIS, R. P. AND THOMAS, w. T. B. 1990. The effects of major genes on quantitatively varying characters in barley 3. The two row/six row locus $(\mathrm{V}-\mathrm{v})$. Heredity, 65, 259-264.

POWELL, W., CALIGARI, P. D. S., SWANSTON, J. S. AND JINKS, J. L. 1985 a. Genetical investigations into $\beta$-glucan content in barley. Theor. Appl. Genet., 71, 461-446.

POWELL, W., CALIGARI, P. D. S., THOMAS, W. T. B. AND JINKS, J. L. $1985 \mathrm{~b}$. The effects of major genes on quantitatively varying characters in barley 2. The denso and daylength responce loci. Heredity, 54, 349-352.

POWELL, W., THOMAS, W. T. B., CALIGAR1, P. D. S. AND JINKS, J. L. 1985c. The effects of major genes on quantitatively varying characters in barley 1 . The GPert locus. Heredity, 54, 343-348.

RIGGS, T. J. AND HAYTER, A. M. 1976. Practical aspects of the single seed descent method in barley breeding. Barley Genetics III. Proceedings third international Barley Genetics Symposium., Garching 1975, Verlag Karl Thiemig, Munich.pp. 708-717.

RIGGS, T. J., HANSON, P. R., START, N. D., MILES, D. M., MORGAN, C. L. AND FORD, M. A. 1981. Comparison of spring barley varieties grown in England and Wales between 1880 and 1980. J. Agric. Sci., Camb., 97, 599-610.

SNAPE, J. W. AND SIMPSON, E. 1981a. Uses of doubled haploid lines for genetical analysis in barley. Barley Genetics $I V$. Proceedings of the Fourth International Barley Genetics Symposium., Edinburgh 1981, Edinburgh University Press, Edinburgh. pp. 704-709.

SNAPE, J. W. AND SIMPSON, E. 1981b. The genetical expectations of doubled haploid lines derived from different filial generations. Theor. Appl. Genet., 60, 123-128.

SWANSTON, J. S. AND TAYLOR, K. 1990. The effects of different steeping regimes on water uptake uptake, germination rate milling energy and hot water extract. J. Inst. Brew., 96, 3-6.

SWANSTON, J. S., TAYLOR, K. AND ALLISON, M. J. 1991. The relationship between grain and malt milling energy in cultivars of spring barley. In: Proceedings of the Third Institute of Brewing Conference on Malting, Brewing and Distilling, Aviemore 1990 (in press).

THOMAS, w. T. B., POWELL, w. AND wOOD, w. 1984. The chromosomal location of the dwarfing gene present in the spring barley variety Golden Promise. Heredity, 53, 177-183. 